\title{
Building Capacity to Improve Child Cognitive Skills: A Case Study
}

\author{
Pooja Verma $^{1 *}$, Dr. Pubalin Das ${ }^{2}$
}

\section{ABSTRACT}

The term capacity building has been utilized as a part of strategies and process which can enhance cognitive skills. Apart from capacity building, this study investigated the role of cognitive technique to improve child outcomes through thinking strategies. The childhood years are critical for human development. It is the time when the brain develops most rapidly and a large number of children's development take place and it is estimated that over 200 million children under 5 years of age are unable to attain their full developmental potential. Studies suggest that young children are quite limited in their knowledge about cognitive phenomena—or in their Meta cognition-and do relatively little monitoring of their own memory, comprehension, and other cognitive enterprises.

The participant in the present study is from the nuclear family. As per the parents and teacher's remark the child thinking process was below average. After doing the assessment the intervention was to develop standard procedure of thinking strategy areas that were assigned to 1 of 4 areas: Memory (e.g., measures associative memory through five item),Concept development (e.g., it included object concept and relational concepts), Reasoning (entail insight and using deductive and inductive logic), problem solving (it is related to arithmetic or quantitative situation). The treatment was evaluated by assessing the child again and qualitatively by means of interview with child, parents and teacher. The results shows that increase in the children's cognitive skills through different thinking strategies.

Keywords: Children, Thinking Strategies, Cognitive Abilities.

Children increase cognitive skills hastily inside the first few years of life and construct on them gradually all through grade school. In this paper the intervention was to develop standard procedure of thinking strategy areas that were assigned approximately four important cognitive skills, as well as discover cognitive milestones from two to 12 years of age. Cognitive skill development in children involves the progressive building of learning skills, such as attention,

\footnotetext{
${ }^{1}$ Consult Psychologist, Mewar University, Ghaziabad, Utter Pradesh, India

${ }^{2}$ Professor, Mewar University, Ghaziabad, Utter Pradesh, India

*Responding Author

(C) 2016, P Verma, P Das; licensee IJIP. This is an Open Access Research distributed under the terms of the Creative Commons Attribution License (http://creativecommons.org/licenses/by/2.0), which permits unrestricted use, distribution, and reproduction in any Medium, provided the original work is properly cited.
} 


\section{Building Capacity to Improve Child Cognitive Skills: A Case Study}

memory and thinking. Although some cognitive skill development is related to a child's genetic makeup, most cognitive skills are learned. That means thinking and learning skills can be improved with practice and the right training. Psychological technological know-how has used measures of several cognitive standards to assess version in area-impartial mental abilities, including processing speed (how efficiently information can be processed (Kail \& Salthouse, 1994), working memory capacity (how much information can be simultaneously processed and maintained in mind (Cowan, 2005; Gathercole, Pickering, Knight, \& Stegmann, 2004), and fluid reasoning (how well novel problem can be solved; also termed fluid g (Engle, Tuholski, Laughlin, \& Conway, 1999 The cognitive capabilities includes thinking strategies eg., memory, auditory processing, visual processing, processing speed, and logic \& reasoning. Those also are the equal talents that IQ assessments diploma to be able to determine IQ. Running together, all of those cognitive skills play important roles in processing new facts. Which means if even this sort of skills is weak, regardless of what kind of records is coming your manner, grasping, keeping, or using that statistics is impacted of child.

ATTENTION When a child learns to pay attention, it enables him to concentrate on one task or conversation for an extended period of time. Learning to focus attention is an important cognitive skill that the child will use in virtually all future learning. Research suggests that Children younger than five years of age tend to have short attention spans that typically last 15 minutes or less. By the time a child reaches eight years of age, he should have an increased ability to focus on one thing for longer periods and complete tasks. He also should be more adept at ignoring distractions. Parents and teachers can help a child develop his ability to focus by pointing out things that seem important or interesting and then asking the child to comment on his observations.

Memory is an important cognitive skill that equips a child to retain what he has learned and experienced and therefore build a future base of knowledge. Children younger than five years of age have difficulty with short- and long-term memory retention. But, as a child progresses into the school years, his long-term memory increases and allows the child to progressively build on the previous knowledge.

Thinking The ability to think includes being able to reason out tasks and find solutions. This cognitive skill helps a child to know whether he's accomplishing what he set out to do or whether he needs to ask for help.

\section{METHOD}

\section{Objective of the Study:}

The main objective of the study is to improve child Cognitive skills through different thinking strategies.

\section{Experimental Design:}

A single case "ABA" experimental design was used to evaluate the effects of strategies. Thirty sessions of reasoning and problem solving strategies has been done in his treatment. 


\section{Building Capacity to Improve Child Cognitive Skills: A Case Study}

\section{Case History}

In the present research case study method is used. In this case study a boy name is Raghav (name changed) of 10 year. He studies in $4^{\text {th }}$ standard of I.C.S.E board. His father is teacher and mother is a house wife. He is the elder and has one younger sister. His sister is 4 years old. Raghav is a pre-mature child. During his mother pregnancy, she has faced lots of medical issues. He is a czarina child. His birth weight was $1.4 \mathrm{~kg}$ because of pre-mature delivery. He was admitted in NICU for 20 days.

When Raghav was seven month from that time he was staying with his maternal grandparents. He was brought up their only. He is more attached to his maternal grandmother. He is very active child. He likes to play cricket, video games. He does not sit one place or properly. He likes to study English. He doesn't like to do mathematic. His father wants that he should do well in math but he is poor in math . He also tries to do well but when he is not able to solve, he feels irritated. He is aggressive in nature. He finds difficulty to solve his own problem. He becomes very angry when he was unable to deal with any situation and become frustrated. He does have the habit of splitting on others face, slapping and hitting. To resolve his issues we have done further measures. Parents and teacher interview were taken and found that child was facing difficulty in studies and problem to solve issues of day to day life. SWARUP-MEHTA TEST OF THINKING STRATEGIES was conducted on this child to see the cognitive skills. Scores may be derived for four sessions (i.e., memory, reasoning, concept Development and Problem solving). After the test conduction has found that child was facing difficulties in reasoning and Problem solving. A time table was constructed in which reasoning and Problem solving Strategies were used on child to enhance their cognitive skills. In that table thirty sessions are included.

Fifteen session of reasoning and fifteen session of problem solving strategies were applied in his cognitive skills modification. Each session is of one hour.

Raghav was dressed in a simple way. He was not stable and moving here and there. Holding the things kept in their place. He threw some of them. When he was asked to sit, he didn't respond. Even he didn't have patience to listen what the others were saying to him. First day he didn't have patience.

During the session at initial stage the child was very disruptive and don't want to work with us. He wants to go out and sit with parents. In the first few session rapport was developed with a child. He was much interested in playing and talking. Both the skills goes on simultaneously The reasoning skills session were taking place that is the action of thinking about something in logic in a sensible way. In these skills we have given Jumble word and picture completion strategies. Jumble word strategy is a word puzzle with a clue a drawing illustrating the clue, and a set of words, each of which is jumble. Picture completion is design to measure visual

(c) The International Journal of Indian Psychology, ISSN 2348-5396 (e)| ISSN: 2349-3429 (p) | 107 


\section{Building Capacity to Improve Child Cognitive Skills: A Case Study}

perception and organization, concentration and visual recognition of essential details of object. The Problem solving skill is the process of finding solution to difficult issue. To enhance this skills we have given Draw a pattern strategies we give object to a child to draw and in Make a list strategy ???? To enhance the reasoning and problem skills we have given him set of jumble words, picture completion and Draw a picture and find pattern to do. In the starting given around 5 set of each skill to do. First he was much interested and excited to do something new and started doing it. Than after sometime he started feeling bored and want to play and go outside. Gradually session was proceeded with the increase of numbers and difficulty level. And at initial stage it was bit difficult for him .he feel bored, makes excuse to move and find difficult to do the exercise but we guided and encourage the child to solve the problem and given him reinforcement like make star and simile on his hand .On later session we found that he started enjoying the session and feel excited to work and he was able to the reasoning strategies with good answers.

\section{RESULT AND DISCUSSION}

It is generally found that children with this age group are facing difficulties in studies. They faced problems in different areas. In the study found that child facing difficulty in Reasoning and problem solving skills.

A profile of the child's total score in each of the area was 67. The total maximum score was 100. It was pre assessment scores. The score of each sub tests in relation to other sub tests reveal the weak and the strong areas in; memory, concept development, reasoning and problem solving are considered to be a very important aspect of child's cognitive functioning. The problem in any one of these area would affect his performance. Studies suggest that these maturing mental abilities are thought to broadly underpin learning and cognitive skills. Variation in these measures predicts performance on a wide range of tasks among adults, including comprehension (Daneman \& Carpenter, 1980), following directions, vocabulary learning, problem solving, and note-taking (Engle, Kane, \& Tuholski, 1999).Critically, these cognitive abilities are associated with academic performance. Executive function measured in preschool predicts performance on math and literacy in kindergarten (Blair \& Razza, 2007)

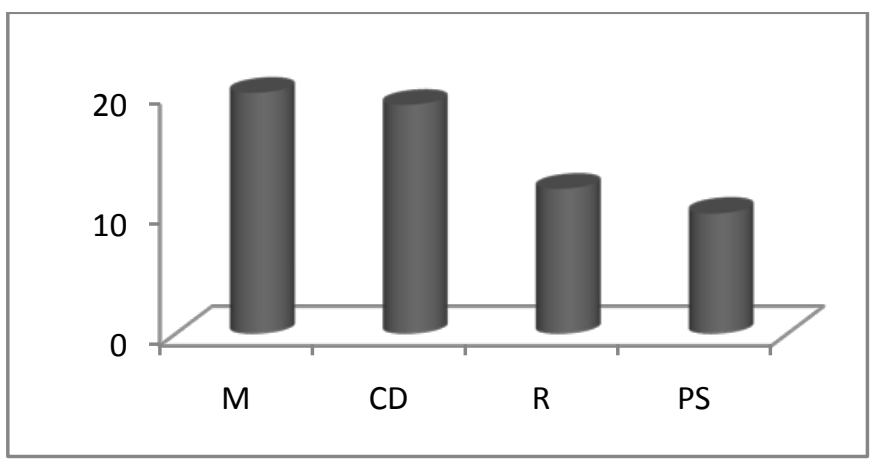

Pre- assessment of the child

(c) The International Journal of Indian Psychology, ISSN 2348-5396 (e)| ISSN: 2349-3429 (p) | 108 


\section{Building Capacity to Improve Child Cognitive Skills: A Case Study}

In the pre-test child performance on memory test as compared to other subtests was better. He performed well in memory. The total score was 20 out of 25, which was good. As per memory the child performance on the concept development would reveal the strength and weakness in the process of abstraction, categorization and generalizing. It can be concluded that the child has knowledge to categorize and generalize and also know the difference between the object. The total score in concept development was 19. The maximum obtainable score on this sub-test was 25. Reasoning is one of the very important aspects of thinking. The child has not done well in reasoning. It indicates that his inductive and deductive both process are below to average, his performance scores reflect upon the bend of his metal process and throw light on his area of difficulty. The total scores were 12 out of 25. Same like reasoning the child was not performed well in problem solving. He was also below to average in this sub-test. The child has difficulty to attacking mathematical problem and also faces the difficulty to recognize the figure. The total scores in problem solving were 10. The maximum obtainable score on this sub-test was 25 . It was concluded after the pre assessment that the child has weak in the problem solving and reasoning. Although several studies have identified some of the cognitive difficulties in problem solving in children at risk for math difficulties (Swanson and Beebe-Frankenberger, 2004; Andersson, 2010; Fuchs et al., 2010; Geary, 2010).

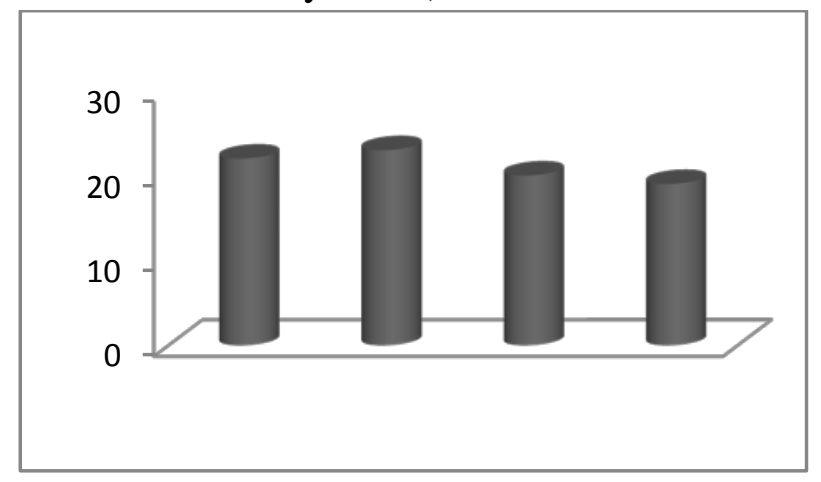

Post Assessment Scores

After the pre assessment thirty sessions were taking and per sessions was for one hour. It was 3 month sessions programmed. In these sessions different strategies use for enhance his problem solving and concept development skills. In the beginning of the sessions the child feel bored or low confidence that he cannot do this work but with motivational and reinforcement technique use to boost his low confidence and in the last of the sessions it was saw that the child can easily to solve all the problems and give affords to do all the difficulty level. This task assessed the child's ability to remember numerical information embedded in a short sentence (Swanson, 1992, 2013).

After completing the all sessions again post assessment was conducting and it saw that there was difference between the result of pre and post assessment. The child got 67 total scores in pre-test but in the post assessment he got 84 scores. The each area was improved compared to pre- test. Especially the area of reasoning and problem solving was improved the scores of the reasoning was now 20 and in the problem solving he got 19 marks out of the 25. Previous studies show that

(C) The International Journal of Indian Psychology, ISSN 2348-5396 (e)| ISSN: 2349-3429 (p) | 109 


\section{Building Capacity to Improve Child Cognitive Skills: A Case Study}

adjusted post-test scores in problem solving accuracy were a function of the type of strategy instruction implemented as well as WMC capacity at pretest (Swanson et al., 2013b; Swanson, 2014).

\section{Acknowledgments}

The author appreciates all those who participated in the study and helped to facilitate the research process.

\section{Conflict of Interests}

The author declared no conflict of interests.

\section{REFERENCE}

Andersson, U.(2010). Skill development in different component so arithmetic and basic cognitive functions: findings from a 3-year longitudinal study of children with different types of learning difficulties. J. Educ. Psychol. 102, 115-134. doi: 10.1037/a0016838.

Blair, C., \& Razza, R. P. (2007). Relating effortful control, executive function, and false belief understanding to emerging math and literacy ability in kindergarten. Child Development, 78(2), 647-663.

Cowan, N. (2005). Working memory capacity: essays in cognitive psychology. New York: Psychology Press; Taylor \& Francis Group.

Daneman, M., \& Carpenter, P. A. (1980). Individual differences in working memory and reading. Journal of Verbal Learning \& Verbal Behavior, 19(4), 450-466.

Engle, R. W., Tuholski, S. W., Laughlin, J. E., \& Conway, A. R. A. (1999). Working memory, short term memory, and general fluid intelligence: A latent-variable approach. Journal of Experimental Psychology: General, 128(3), 309-331.

Fuchs, L. S., Geary, D. C., Compton, D. L., Fuchs, D., Hamlett, C. L., and Seethaler, P. M. (2010). Do different types of school mathematics development depend on different constellations of numerical versus general cognitive abilities? Dev. Psychol. 46, 17311746. doi: $10.1037 / \mathrm{a} 0020662$

Geary, D. C. (2010). Mathematical disabilities: reflections on cognitive, neuropsychological, and genetic components. Learn. Individual. Differ. 20, 130-133. doi: 10.1016/j.lindif.2009.10.008

Kail, R., \& Salthouse, T. A. (1994). Processing speed as a mental capacity. Act Psychological, 86(2-3), 199-225.

Swanson, H. L. (1992). Generality and modification of working memory among skilled and less skilled readers. J. Educ. Psychol. 84, 473-488. doi: 10.1037/0022- 0663.84.4.473

Swanson, H. L. (2013).Abbreviated Test of Working Memory. Washington, DC: American Psychological Association. 


\section{Building Capacity to Improve Child Cognitive Skills: A Case Study}

Swanson, H. L. (2014). Does cognitive strategy training on word problems compensate for working memory capacity in children with math difficulties? J. Educ. Psychol. 106, 831848. doi: 10.1037/a0035838.

Swanson, H. L., and Beebe-Frankenberg, M. (2004).The relationship between working memory and mathematical problem solving in children at risk and not a risk for serious math difficulties. J. Educ. Psychol. 96, 471-491. doi: 10.1037/0022-0663.96.3.471

Swanson, H. L., Moran, A. S., Bocian, K., Lussier, C., and Zheng, X. (2013b). Generative strategies, working memory, and word problem solving accuracy in children at risk for math disabilities. Learn. Disable. Q. 36, 203-214. doi: 10.1177/0731948712464034

How to cite this article: P Verma, P Das (2016), Building Capacity to Improve Child Cognitive Skills: A Case Study, International Journal of Indian Psychology, Volume 3, Issue 4, No. 67, ISSN:2348-5396 (e), ISSN:2349-3429 (p), DIP:18.01.185/20160304, ISBN:978-1-365-39397-6 